\title{
Depletion of microglia ameliorates white matter injury and cognitive impairment in a mouse chronic cerebral hypoperfusion model
}

\section{$\operatorname{AUTHOR(S):~}$}

Kakae, Masashi; Tobori, Shota; Morishima, Misa; Nagayasu, Kazuki; Shirakawa, Hisashi; Kaneko, Shuji

\section{CITATION:}

Kakae, Masashi ...[et al]. Depletion of microglia ameliorates white matter injury and cognitive impairment in a mouse chronic cerebral hypoperfusion model. Biochemical and Biophysical Research Communications 2019, 514(4): 1040-1044

\section{ISSUE DATE:}

2019-07-05

URL:

http://hdl.handle.net/2433/241701

\section{RIGHT:}

(c) 2019. This manuscript version is made available under the CC-BY-NC-ND 4 . 0 license

http://creativecommons.org/licenses/by-nc-nd/4.0/; The full-text file will be made open to the public on 5 July 2020 in accordance with publisher's 'Terms and Conditions for Self-Archiving'.; This is not the published version. Please cite only the published version.; この論文は出版社版でありません。引用の際には出版社版をご確認ご利用ください。 


\title{
Depletion of microglia ameliorates white matter injury and cognitive impairment in a mouse chronic cerebral hypoperfusion model
}

\author{
Masashi Kakae, ${ }^{\text {a }}$ Shota Tobori, ${ }^{\text {a }}$ Misa Morishima, ${ }^{\text {a }}$ Kazuki Nagayasu, ${ }^{\text {a }}$ Hisashi \\ Shirakawa, ${ }^{\mathrm{a}, *}$ and Shuji Kaneko ${ }^{\mathrm{a}}$
}

aDepartment of Molecular Pharmacology, Graduate School of Pharmaceutical Sciences, Kyoto University, 46-29 Yoshida-Shimoadachi-cho, Sakyo-ku, Kyoto 606-8501, Japan

*Corresponding author:

Hisashi Shirakawa, PhD, 46-29 Yoshida-shimoadachi-cho, Sakyo-ku, Kyoto 606-8501, Japan. Tel.: +81-75-753-4549; Fax: +81-75-753-4548; E-mail:

shirakaw@pharm.kyoto-u.ac.jp 


\section{Abstract}

Microglia are immune cells in the central nervous system (CNS) and essential for homeostasis that are important for both neuroprotection and neurotoxicity, and are activated in a variety of CNS diseases. Microglia aggravate cognitive impairment induced by chronic cerebral hypoperfusion, but their precise roles under these conditions remain unknown. Here, we used PLX3397, a colony-stimulating factor 1 receptor inhibitor, to deplete microglia in mice with chronic cerebral hypoperfusion induced by bilateral common carotid artery stenosis (BCAS). Cognitive impairment induced 28 days after BCAS was significantly improved in mice fed a diet containing PLX3397. In PLX3397-fed mice, microglia were depleted and white matter injury induced by BCAS was suppressed. In addition, the expression of proinflammatory cytokines, interleukin 6 and tumor necrosis factor alpha, was suppressed in PLX3397-fed mice. Taken together, these findings suggest that microglia play destructive roles in the development of cognitive impairment and white matter injury induced by chronic cerebral hypoperfusion. Thus, microglia represent a potential therapeutic target for chronic cerebral hypoperfusion-related diseases.

Keywords: chronic cerebral hypoperfusion, cognitive impairment, white matter injury, microglia, cytokines, colony-stimulating factor 1

Abbreviations: BCAS, bilateral common carotid artery stenosis; CNS, central nervous system; GSTpi, glutathione S-transferase Pi; CSF1R, colony-stimulating factor 1 
receptor; IL6, interleukin 6; TNF $\alpha$, tumor necrosis factor alpha 


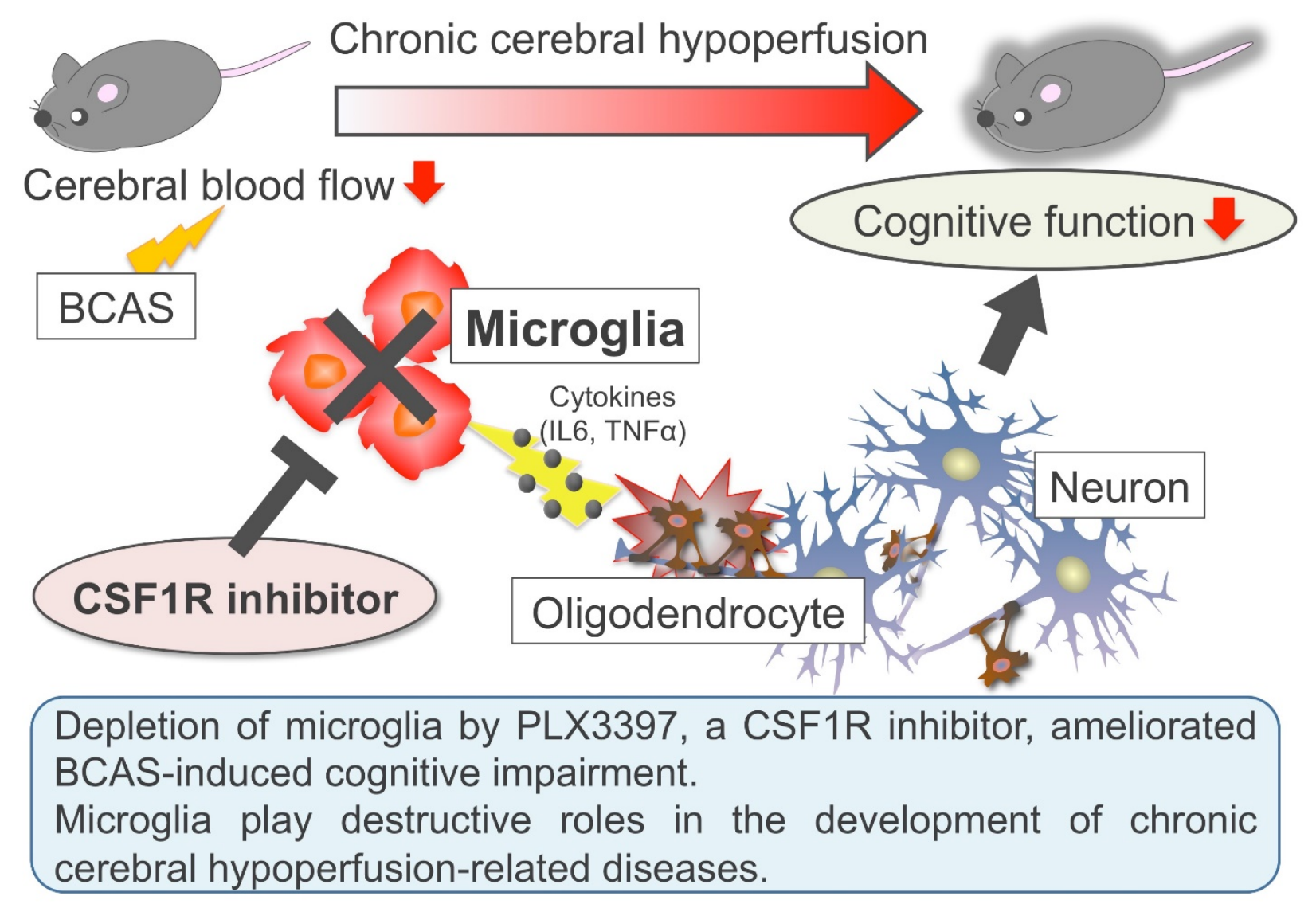




\section{Introduction}

Microglia are immune cells in the central nervous system (CNS) [1] that maintain CNS homeostasis [2]. These cells are important for both neuroprotection and neurotoxicity and are activated in a variety of CNS diseases, such as Alzheimer's disease [3], frontotemporal dementia [4], and ischemic stroke [5], and aging [6]. Dystrophic changes to microglia occur in the aged human brain [7], and recent studies suggest that microglia exhibit regional diversity and sensitivities to aging, with multiple subtypes activated in a variety of CNS diseases $[8,9]$. However, the precise protective and destructive roles of microglia and their contributions to disease have not been completely elucidated.

Chronic cerebral hypoperfusion contributes to the progression of inflammatory responses [10], and chronic cerebral hypoperfusion-induced cognitive impairment is highly associated with inflammation in mice [11] and humans [12]. We previously demonstrated that the activation of microglia via transient receptor potential melastatin 2, a $\mathrm{Ca}^{2+}$-permeable channel abundantly expressed in immune cells, aggravates this cognitive impairment [13]. In the present study, to clarify the role of microglia in this effect, we examined the pathophysiology of chronic cerebral hypoperfusion in mice administered a colony-stimulating factor 1 receptor (CSF1R) inhibitor that has been shown to deplete microglia [14]. CSF1R is an essential regulator of myeloid lineage cells. Dietary treatment of mice with the CSF1R inhibitor PLX3397 for 21 days depletes virtually all microglia and has very few effects on peripheral myeloid cells and neurological function [15]. Mice were fed a diet containing PLX3397 for 21 days before 
undergoing bilateral common carotid artery stenosis (BCAS) to induce chronic cerebral hypoperfusion. We then performed cognitive assessments in these mice and examined the extent of white matter damage.

\section{Materials and Methods}

\section{Animals and food}

All experiments were conducted in accordance with the ethical guidelines of the Kyoto University animal experimentation committee and with the guidelines of the Japanese Pharmacological Society. Male C57BL/6J mice (8-12 weeks old, 20-30 g) were purchased from Japan SLC. All mice were housed at a constant ambient temperature of $22 \pm 2^{\circ} \mathrm{C}$ under a $12 \mathrm{~h}$ light/dark cycle and given ad libitum access to water and food.

To deplete microglia, mice were fed chow containing PLX3397 (290 mg/kg) for 21 consecutive days prior to BCAS and until the end of experiments. Control mice were fed standard chow.

\section{BCAS}

Mice were subjected to BCAS using microcoils with an internal diameter of 0.18 mm (Sawane Spring), as previously described $[13,16]$. First, mice were anesthetized with $3 \%$ isoflurane in $30 \% \mathrm{O}_{2}$ and $70 \% \mathrm{~N}_{2} \mathrm{O}$ and maintained on $1.5 \%$ isoflurane in $30 \%$ $\mathrm{O}_{2}$ and $70 \% \mathrm{~N}_{2} \mathrm{O}$ using a face mask. After a midline skin incision, the microcoil was applied to the bilateral common carotid arteries. Control animals were subjected to a 
sham operation in which the bilateral common carotid arteries were isolated but the microcoil was not applied.

\section{Novel object recognition test}

The novel object recognition test was performed 28 days after the surgery. Mice were habituated to a black box $(30 \times 30 \times 30 \mathrm{~cm})$ for 3 days $(10$ min a day) under dim illumination (30 lux). In the training session, the mice were allowed to freely interact for 10 min with two different objects (a yellow triangular prism and a blue quadrangular pyramid) placed in the box. $6 \mathrm{~h}$ later, the blue quadrangular object was replaced with a novel wooden ball in the test session. The total exploratory time was defined as the time spent exploring both of the objects, and was considered an indicator of locomotor activity. Exploratory preference was defined as the ratio of the time spent exploring the blue quadrangular object in the training session and the wooden ball in the test session versus the total time spent exploring both of the objects and was considered an indicator of recognition memory.

\section{Myelin staining}

Mice were intraperitoneally injected with $50 \mathrm{mg} / \mathrm{kg}$ body weight pentobarbital or a cocktail of three different anesthetic agents $(0.3 \mathrm{mg} / \mathrm{kg}$ medetomidine, $4.0 \mathrm{mg} / \mathrm{kg}$ midazolam, and $5.0 \mathrm{mg} / \mathrm{kg}$ butorphanol) and perfused transcardially with $\mathrm{K}^{+}$-free phosphate-buffered saline followed by $4 \%$ paraformaldehyde in $0.1 \mathrm{M}$ phosphate buffer. Brains were stored in the fixative for $3 \mathrm{~h}$ and then transferred to $15 \%$ sucrose in $0.1 \mathrm{M}$ 
phosphate buffer for $24 \mathrm{~h}$. Coronal sections ( $20 \mu \mathrm{m}$ ) were cut using a cryomicrotome and incubated in $0.1 \%$ Triton X-100 in phosphate-buffered saline for at least $20 \mathrm{~min}$. The sections were then incubated with Fluoromyelin green (1:1000; Invitrogen) for 20 min at room temperature. Fluorescence was visualized with an Olympus Fluoview microscope equipped with a laser scanning confocal imaging system. The mean intensity of Fluoromyelin staining in the corpus callosum was measured in a $200 \times 200$ $\mu \mathrm{m}$ field at approximately $0.7 \mathrm{~mm}$ anterior to bregma.

\section{Immunofluorescence}

Coronal sections were incubated overnight at $4{ }^{\circ} \mathrm{C}$ with primary rabbit antibodies for glutathione S-transferase Pi (GSTpi) (1:200; MBL Life Science) or Iba1 (1:500; Wako Pure Chemical Industries). Sections were then incubated with fluorescent-labeled secondary antibodies (Alexa Fluor 488- or 594-labeled donkey anti-rabbit IgG, 1:300; Invitrogen) at room temperature for $1.5 \mathrm{~h}$ in the dark. Images were captured with a confocal fluorescence microscope. Iba1-positive cells in a $0.125 \mathrm{~mm}^{2}$ field of the corpus callosum $0.7 \mathrm{~mm}$ anterior to bregma were counted.

\section{Real-time PCR}

Samples of the corpus callosum were dissected from 2 mm-thick coronal brain slices and immediately frozen in liquid nitrogen for storage at $-80^{\circ} \mathrm{C}$ until use. Total RNA was isolated using ISOGEN reagent (Nippon Gene) in accordance with the manufacturer's suggested protocols, and cDNA was synthesized from $1 \mu \mathrm{g}$ of total RNA 
using ReverTra Ace (Toyobo). Real-time quantitative PCR was performed using the StepOne real-time PCR system (Life Technologies). The final reaction volume was 20 $\mu \mathrm{l}$ (25 ng of cDNA plus THUNDERBIRD SYBR qPCR mix; Toyobo). The PCR conditions were as follows: $10 \mathrm{~min}$ at $95^{\circ} \mathrm{C}$, followed by 40 cycles at $95^{\circ} \mathrm{C}$ for $10 \mathrm{~s}$ and $60^{\circ} \mathrm{C}$ for $1 \mathrm{~min}$. The following oligonucleotide primers were used: interleukin 6 (IL6), 5'-GTG GCT AAG GAC CAA GAC CA-3' and 5'-TAA CGC ACT AGG TTT GCC GA-3'; tumor necrosis factor alpha (TNF $\alpha)$, 5'-TGC CTA TGT CTC AGC CTC TTC-3' and 5'-GAG GCC ATT TGG GAA CTT CT-3'; and 18S rRNA, 5'-GCA ATT ATT CCC CAT GAA CG-3' and 5'-GGC CTC ACT AAA CCA TCC AA-3'. The amount of 18S rRNA in samples was used to normalize the mRNA content (the mRNA level was expressed relative to that of the corresponding control).

\section{Experimental design and statistical analysis}

Statistical analysis was performed using Prism 7 software (GraphPad Software). Briefly, for comparisons between multiple experimental groups, a two-way analysis of variance with Bonferroni's post hoc test was used as appropriate. In all cases, a $P$ value of $<0.05$ was considered statistically significant. Data are given as means \pm SEM.

Each data point in the figures represents one sample (section or corpus callosum sample) from one mouse. The numbers of animals used in each experiment are indicated in the figure legends. The assessor was blinded to treatment conditions.

\section{Results}




\section{Assessment of BCAS-induced cognitive impairment and the effect of microglial}

\section{depletion}

Cognitive impairment was assessed with the novel object recognition test 28 days after BCAS in mice fed PLX3397-containing chow or control diet beginning 21 days before the surgery (Fig. 1A). There were no differences between the groups in the total time spent exploring the two objects during the training and test sessions (Fig. 1B, C), demonstrating that the BCAS operation and microglial depletion did not affect locomotor activity. Exploratory preferences for the two different objects were $~ 50 \%$, and there were no differences between the groups during the training session (Fig. 1D). However, BCAS-operated mice displayed a significantly reduced exploratory preference for the novel object compared with that by the sham group fed the control diet, and the decrease was significantly attenuated in the PLX3397-fed group during the test session (Fig. 1E). These results imply that the depletion of microglia ameliorates cognitive impairment induced by chronic cerebral hypoperfusion.

\section{Assessment of microglial depletion and BCAS-induced white matter injury}

Histological assays were performed 28 days after BCAS to assess microglial depletion and white matter injury (Fig. 2A). Microglial depletion by PLX3397 was confirmed by immunostaining for Iba1, a marker of microglia and macrophages, in the corpus callosum (Fig. 2B, C). Whereas control diet-fed mice displayed a significant increase in the number of Iba1-positive cells 28 days after BCAS, microglial depletion was maintained in PLX3397-fed mice. These results show that BCAS induces activation 
of microglia and that these cells remain depleted in animals treated with PLX3397.

As white matter injury is a characteristic of chronic cerebral hypoperfusion [13, 17] and associated with cognitive impairment in vascular dementia [18], we assessed myelin staining in the corpus callosum after chronic cerebral hypoperfusion with and without microglial depletion. In BCAS-operated control diet-fed mice, there was a tendency to decrease in myelin density compared with that in the sham controls. By contrast, PLX3397-fed mice did not exhibit this decrease and had a significantly greater myelin density than control diet-fed mice after BCAS (Fig. 2D, E). Moreover, immunostaining for GSTpi revealed that BCAS significantly reduced the number of oligodendrocytes in control diet-fed mice but not PLX3397-fed mice (Fig. 2F, G). These results suggest that the depletion of microglia prevents BCAS-induced white matter injury.

\section{BCAS-induced changes in inflammatory responses in the corpus callosum}

To investigate inflammation in chronic cerebral hypoperfusion, the expression of proinflammatory cytokines in the corpus callosum was measured by real-time quantitative PCR 14 days after BCAS (Fig. 3A), a time at which we previously determined that there is an increase in proinflammatory cytokines and microglial markers [13]. IL6 mRNA expression was significantly increased after BCAS in control diet-fed mice and significantly lower in PLX3397-fed mice (Fig. 3B). Similarly, the expression of TNF $\alpha$ was significantly suppressed in PLX3397-fed mice after BCAS (Fig. 3C). These results suggest that the depletion of microglia reduces inflammatory 
responses to chronic cerebral hypoperfusion.

\section{Discussion}

In the present study, we showed that the depletion of microglia by PLX3397 suppressed inflammation, white matter injury, and cognitive impairment induced by BCAS, suggesting that the activation of microglia contributes to a variety of pathological changes induced by chronic cerebral hypoperfusion.

In our previous study, we found that the inhibition of microglial activation by minocycline, a tetracycline antibiotic, ameliorated the white matter injury and cognitive impairment induced by BCAS [13]. Therefore, we concluded that microglia play important roles in chronic cerebral hypoperfusion-related changes. However, minocycline also inhibits the activation of macrophages [19] and astrocytes [20,21] as well as 5-lipoxygenase [22]. To confirm that the benefits were a result of microglial effects, here we treated the mice with the CSF1R inhibitor PLX3397, which along with PLX5622 has been used in a wide variety of CNS disease studies. For example, CSF1R inhibitors decrease lesion size, brain edema, and neurological deficits in a mouse intracerebral hemorrhage model [23], and CSF1R inhibitor-induced depletion of microglia suppresses neuritic plaque accumulation and improves cognitive impairment in a mouse model of Alzheimer's disease [24]. In this context, the study using aging mice showed that repopulation of microglia after elimination by the CSF1R inhibitor restores microglial morphology (repopulated cells resemble young cells) and ameliorates age-related cognitive dysfunction [25]. Other studies indicate that the 
depletion of microglia also improves neurological deficits in mouse models of demyelination-related diseases, such as catatonia [26] and multiple sclerosis [27, 28]. However, Jin et al. found that brain infarctions and neurological deficits were exacerbated by the depletion of microglia in mice with middle cerebral artery occlusion, a model of focal cerebral ischemia [29], suggesting that microglia restricted the ischemia-induced astrocyte response and conferred neuroprotective function. Moreover, physical exercise has also been shown to alleviate cognitive impairment and demyelination in a two-vessel occlusion model of chronic cerebral hypoperfusion in rats, in which the benefit was associated with a polarization from M1 toward M2 microglia [30]. Because treatment with PLX3397 in the present study eliminated virtually all microglia, including M1 and M2 subtypes, further investigations are required to clarify the difference of microglial subtypes in chronic cerebral hypoperfusion-related diseases.

IL6 and TNF $\alpha$ are cytokines that are secreted by astrocytes as well as microglia [31]. The expression of these cytokines was reduced by PLX3397 in BCAS-operated mice as well as in sham-operated mice, suggesting that microglia are primarily responsible for the expression of IL6 and TNF $\alpha$ in the corpus callosum. However, the reduced expression in animals treated with PLX3397 may have resulted in reduced signaling in astrocytes, as they express the receptors for IL6 and TNF $\alpha$ among others [32]. Therefore, further investigations into the involvement of astrocytes in chronic cerebral hypoperfusion are needed. Nevertheless, the findings implicate the secretion of proinflammatory cytokines from microglia in the cognitive impairment and white matter injury induced by BCAS. 
In conclusion, the results of this study indicate that microglia play destructive roles in chronic cerebral hypoperfusion-related diseases. The timing of microglial activation in relation to the associated white matter injury and cognitive impairment is unclear, as the depletion was initiated 21 days before BCAS in the present study. Studies with PLX5622, a CSF1R inhibitor that eliminates microglia with just 7 days of treatment, may help to clarify this and to determine the time point at which microglial depletion would be most therapeutic for chronic cerebral hypoperfusion. Additional studies may also elucidate whether and/or how microglial repopulation affects chronic cerebral hypoperfusion-induced outcomes. Nevertheless, the findings presented here indicate that microglia represent a potential therapeutic target for clinical interventions to treat chronic cerebral hypoperfusion-related diseases.

\section{Acknowledgments}

This study was supported by MEXT/JSPS KAKENHI Grant Numbers 17K19486 and 19K03377 (to H.S.). This work was also supported by the Novartis Foundation, the Takeda Science Foundation, and the Kyoto University Research Development Program (Ishizue). 


\section{References}

[1] Q. Li, B. A. Barres, Microglia and macrophages in brain homeostasis and disease, Nat. Rev. Immunol. 18 (2018) 225-242.

[2] M. Prinz, D. Erny, N. Hagemeyer, Ontogeny and homeostasis of CNS myeloid cells, Nat. Immunol. 18 (2017) 385-392

[3] H. Keren-Shaul, A. Spinrad, A. Weiner, O. Matcovitch-Natan, R. Dvir-Szternfeld, T.K. Ulland, E. David, K. Baruch, D. Lara-Astaiso, B Toth, S. Itzkovitz, M. Colonna, M. Schwartz, I. Amit, A Unique Microglia Type Associated with Restricting Development of Alzheimer's Disease, Cell 169 (2017) 1276-1290

[4] E.L. Clayton, R. Mancuso, T.T. Nielsen, S. Mizielinska, H. Holmes, N. Powell, F. Norona, J.O. Larsen, C. Milioto, K.M. Wilson, M.F. Lythgoe, S. Ourselin, J.E. Nielsen, P. Johannsen, I. Holm, J. Collinge, FReJA, P.L. Oliver, D. Gomez-Nicola, A.M. Isaacs, Early microgliosis precedes neuronal loss and behavioural impairment in mice with a frontotemporal dementia-causing CHMP2B mutation, Hum. Mol. Genet. 26 (2017) 873-887

[5] A.C. Wendeln, K. Degenhardt, L. Kaurani, M. Gertig, T. Ulas, G. Jain, J. Wagner, L.M. Häsler, K. Wild, A. Skodras, T. Blank, O. Staszewski, M. Datta, T.P. Centeno, V. Capece, M.R. Islam, C. Kerimoglu, M. Staufenbiel, J.L. Schultze, M. Beyer, M. Prinz, M. Jucker, A. Fischer, J.J. Neher, Innate immune memory in the brain shapes neurological disease hallmarks, Nature 556 (2018) 332-338

[6] M. Kakae, J. Miyanohara, M. Morishima, K. Nagayasu, Y. Mori, H. Shirakawa, S. Kaneko, Pathophysiological Role of TRPM2 in Age-Related Cognitive 
Impairment in Mice, Neuroscience S0306-4522 (19) 30252-0. doi:

10.1016/j.neuroscience.2019.04.012.

[7] R.M. Ransohoff, How neuroinflammation contributes to neurodegeneration, Science 353 (2016) 777-783

[8] B.A. Friedman, K. Srinivasan, G. Ayalon, W.J. Meilandt, H. Lin, M.A. Huntley, Y. Cao, S.H. Lee, P.C.G. Haddick, H. Ngu, Z. Modrusan, J.L. Larson, J.S. Kaminker, M.P. van der Brug, D.V. Hansen, Diverse Brain Myeloid Expression Profiles Reveal Distinct Microglial Activation States and Aspects of Alzheimer's Disease Not Evident in Mouse Models, Cell. Rep. 22 (2018) 832-847

[9] T.R. Hammond, C. Dufort, L. Dissing-Olesen, S. Giera, A. Young, A. Wysoker, A.J. Walker, F. Gergits, M. Segel, J. Nemesh, S.E. Marsh, A. Saunders, E. Macosko, F. Ginhoux, J. Chen, R.J.M. Franklin, X. Piao, S.A. McCarroll, B. Stevens, Single-Cell RNA Sequencing of Microglia throughout the Mouse Lifespan and in the Injured Brain Reveals Complex Cell-State Changes, Immunity 50 (2019) $253-271$

[10] P. Venkat, M. Chopp, J. Chen, Models and mechanisms of vascular dementia, Exp. Neurol. 272 (2015) 97-108

[11] R. Saggu, T. Schumacher, F. Gerich, C. Rakers, K. Tai, A. Delekate, G.C. Petzold, Astroglial NF-kB contributes to white matter damage and cognitive impairment in a mouse model of vascular dementia, Acta. Neuropathol. Commun. 4 (2016) 76

[12] Y. Kawamoto, I. Akiguchi, H. Tomimoto, Y. Shirakashi, Y. Honjo, H. Budka, Upregulated expression of 14-3-3 proteins in astrocytes from human 
cerebrovascular ischemic lesions, Stroke 37 (2006) 830-835

[13] J. Miyanohara, M. Kakae, K. Nagayasu, T. Nakagawa, Y. Mori, K. Arai, H. Shirakawa, S. Kaneko, TRPM2 channel aggravates CNS inflammation and cognitive impairment via activation of microglia in chronic cerebral hypoperfusion, J. Neurosci. 38 (2018) 3520-3533

[14] M.R.P. Elmore, A.R. Najafi, M.A. Koike, N.N. Dagher, E.E. Spangenberg, R.A. Rice, M. Kitazawa, B. Matusow, H. Nguyen, B.L. West, K.N. Green, Colony-stimulating factor 1 receptor signaling is necessary for microglia viability, unmasking a microglia progenitor cell in the adult brain, Neuron 82 (2014) 380-397

[15] G. Szalay, B. Martinecz, N. Lénárt, Z. Környei, B. Orsolits, L. Judák, E. Császár, R. Fekete, B.L. West, G. Katona, B. Rózsa, Á. Dénes, Microglia protect against brain injury and their selective elimination dysregulates neuronal network activity after stroke, Nat. Commun. 7 (2016) 11499

[16] T. Temma, M. Yamazaki, J. Miyanohara, H. Shirakawa, N. Kondo, K. Koshino, S. Kaneko, H. Iida, Sequential PET estimation of cerebral oxygen metabolism with spontaneous respiration of ${ }^{15} \mathrm{O}$-gas in mice with bilateral common carotid artery stenosis, J. Cereb. Blood. Flow. Metab. 37 (2017) 3334-3343

[17] M.A. Daulatzai, Cerebral hypoperfusion and glucose hypometabolism: Key pathophysiological modulators promote neurodegeneration, cognitive impairment, and Alzheimer's disease, J. Neurosci. Res. 95 (2017) 943-972

[18] M. Dichgans, D. Leys, Vascular Cognitive Impairment, Circ. Res. 120 (2017) 
573-591

[19] C.C. Liu, N. Lu, Y. Cui, T. Yang, Z.Q. Zhao, W.J. Xin, X.G. Liu, Prevention of paclitaxel-induced allodynia by minocycline: Effect on loss of peripheral nerve fibers and infiltration of macrophages in rats, Mol. Pain. 6 (2010) 76

[20] C.R. Robinson, H. Zhang, P.M. Dougherty, Astrocytes, but not microglia, are activated in oxaliplatin and bortezomib-induced peripheral neuropathy in the rat, Neuroscience 274 (2014) 308-317

[21] K. Miyamoto, K. Kume, M. Ohsawa, Role of microglia in mechanical allodynia in the anterior cingulate cortex, J. Pharmacol. Sci. 134 (2017) 158-165

[22] Y. Song, E.Q. Wei, W.P. Zhang, L. Zhang, J.R. Liu, Z. Chen, Minocycline protects PC12 cells from ischemic-like injury and inhibits 5-lipoxygenase activation, Neuroreport 15 (2004) 2181-2184

[23] M. Li, Z. Li, H. Ren, W.N. Jin, K. Wood, Q. Liu, K.N. Sheth, F.D. Shi, Colony stimulating factor 1 receptor inhibition eliminates microglia and attenuates brain injury after intracerebral hemorrhage, J. Cereb. Blood. Flow. Metab. 37 (2017) 2383-2395

[24] J. Sosna, S. Philipp, R. Albay 3rd, J.M. Reyes-Ruiz, D. Baglietto-Vargas, F.M. LaFerla, C.G. Glabe, Early long-term administration of the CSF1R inhibitor PLX3397 ablates microglia and reduces accumulation of intraneuronal amyloid, neuritic plaque deposition and pre-fibrillar oligomers in 5XFAD mouse model of Alzheimer's disease, Mol. Neurodegener. 13 (2018) 11 
[25] M.R.P. Elmore, L.A. Hohsfield, E.A. Kramár, L. Soreq, R.J. Lee, S.T. Pham, A.R. Najafi, E.E. Spangenberg, M.A. Wood, B.L. West, K.N. Green, Replacement of microglia in the aged brain reverses cognitive, synaptic, and neuronal deficits in mice, Aging Cell 17 (2018) e12832.

[26] H. Janova, S. Arinrad, E. Balmuth, M. Mitjans, J. Hertel, M. Habes, R.A. Bittner, H. Pan, S. Goebbels, M. Begemann, U.C. Gerwig, S. Langner, H.B. Werner, S. Kittel-Schneider, G. Homuth, C. Davatzikos, H. Völzke, B.L. West, A. Reif, H.J. Grabe, S. Boretius, H. Ehrenreich, K.A. Nave, Microglia ablation alleviates myelin-associated catatonic signs in mice, J. Clin. Invest. 128 (2018) 734-745.

[27] J.C. Nissen, K.K. Thompson, B.L. West, S.E. Tsirka, Csf1R inhibition attenuates experimental autoimmune encephalomyelitis and promotes recovery, Exp. Neurol. 307 (2018) 24-36

[28] F. Tahmasebi, P. Pasbakhsh, K. Mortezaee, S. Madadi, S. Barati, I.R. Kashani, Effect of the CSF1R inhibitor PLX3397 on remyelination of corpus callosum in a cuprizone-induced demyelination mouse model, J. Cell. Biochem. 120 (2019) 10576-10586.

[29] W.N. Jin, S.X. Shi, Z. Li, M. Li, K. Wood, R.J. Gonzales, Q. Liu, Depletion of microglia exacerbates postischemic inflammation and brain injury, J. Cereb. Blood. Flow. Metab. 37 (2017) 2224-2236

[30] T. Jiang, L. Zhang, X. Pan, H. Zheng, X. Chen, L. Li, J. Luo, X. Hu, Physical Exercise Improves Cognitive Function Together with Microglia Phenotype Modulation and Remyelination in Chronic Cerebral Hypoperfusion, Front. Cell. 
Neurosci. 11 (2017) 404

[31] M.V. Sofroniew, Astrocyte barriers to neurotoxic inflammation, Nat. Rev. Neurosci. 16 (2015) 249-263

[32] M.V. Sofroniew, Multiple roles for astrocytes as effectors of cytokines and inflammatory mediators, Neuroscientist. 20 (2014) 160-172 


\section{Figure legends}

Figure 1. BCAS-induced cognitive impairment was not observed in PLX3397-fed mice.

(A) The experimental time course for the novel object recognition test (NORT). Total times spent exploring the two objects during training (B) and test (C) sessions. Exploratory preferences for the two different objects during the training (D) and test (E) sessions. Values are means \pm SEM. ${ }^{* *} P<0.01(n=12-17)$.

Figure 2. BCAS-induced increases in Iba1-positive cells and white matter injury were not observed in PLX3397-fed mice.

(A) The experimental time course for histological assays. Representative images (B) and quantification (C) of Iba1 immunostaining in the corpus callosum ( $n=9-14)$. Representative images of myelin staining (D) and quantification of relative myelin density (E) in the corpus callosum ( $n=9-14)$. Representative images $(F)$ and quantification $(\mathrm{G})$ of GSTpi immunostaining in the corpus callosum $(n=6-11)$. Scale bars, $100 \mu \mathrm{m}$. Values are means \pm SEM. $* P<0.05$, $* * * P<0.001$.

Figure 3. Proinflammatory cytokine expression in the corpus callosum was suppressed in PLX3397-fed mice.

(A) The experimental time course for real-time quantitative PCR. Expression of IL6 (B) and TNF $\alpha(\mathrm{C})$ mRNA in the corpus callosum $(n=3-4)$. Values are means \pm SEM. $* P<$ $0.05, * * P<0.01$. 
Figure 1.
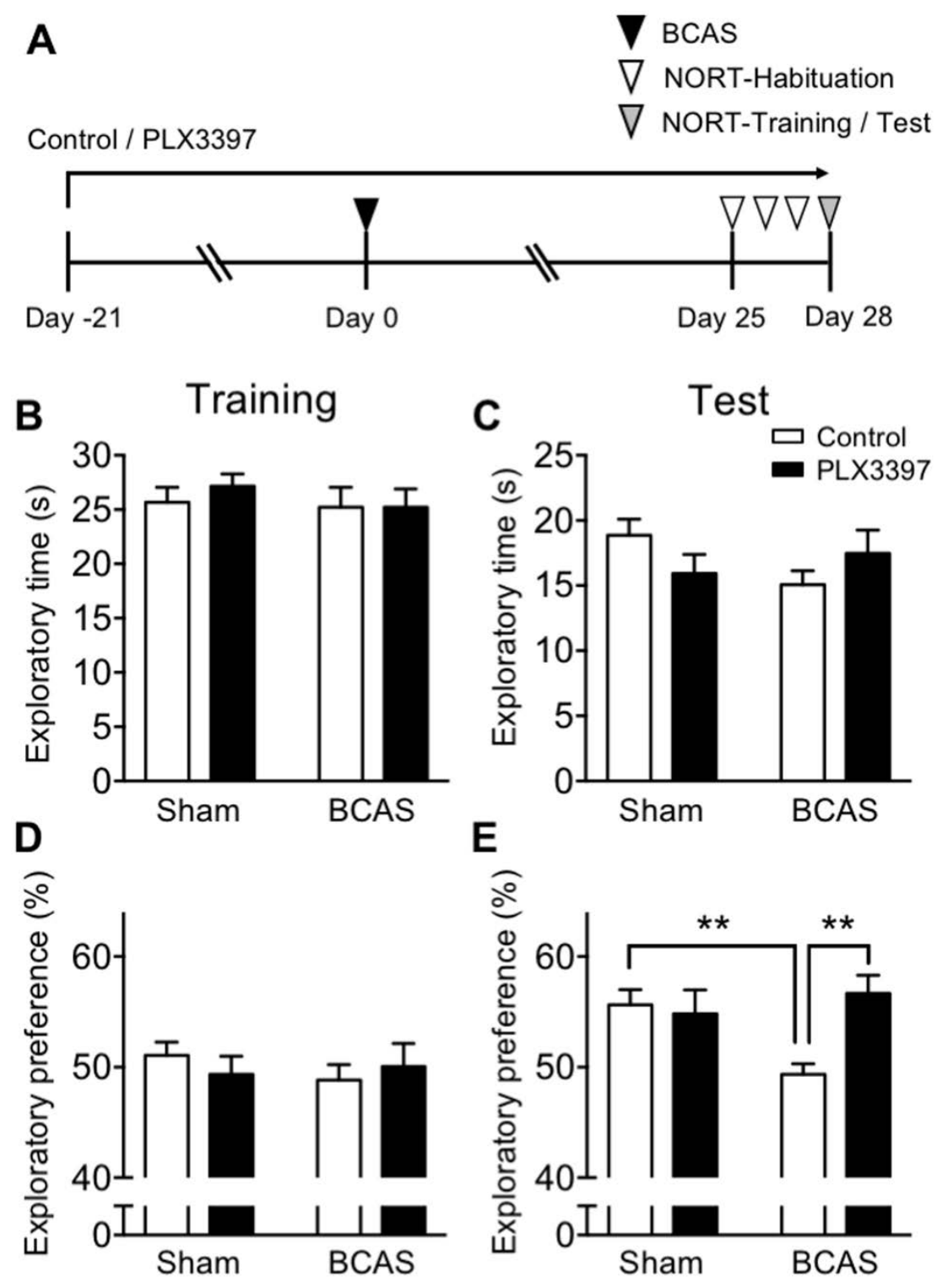
Figure 2

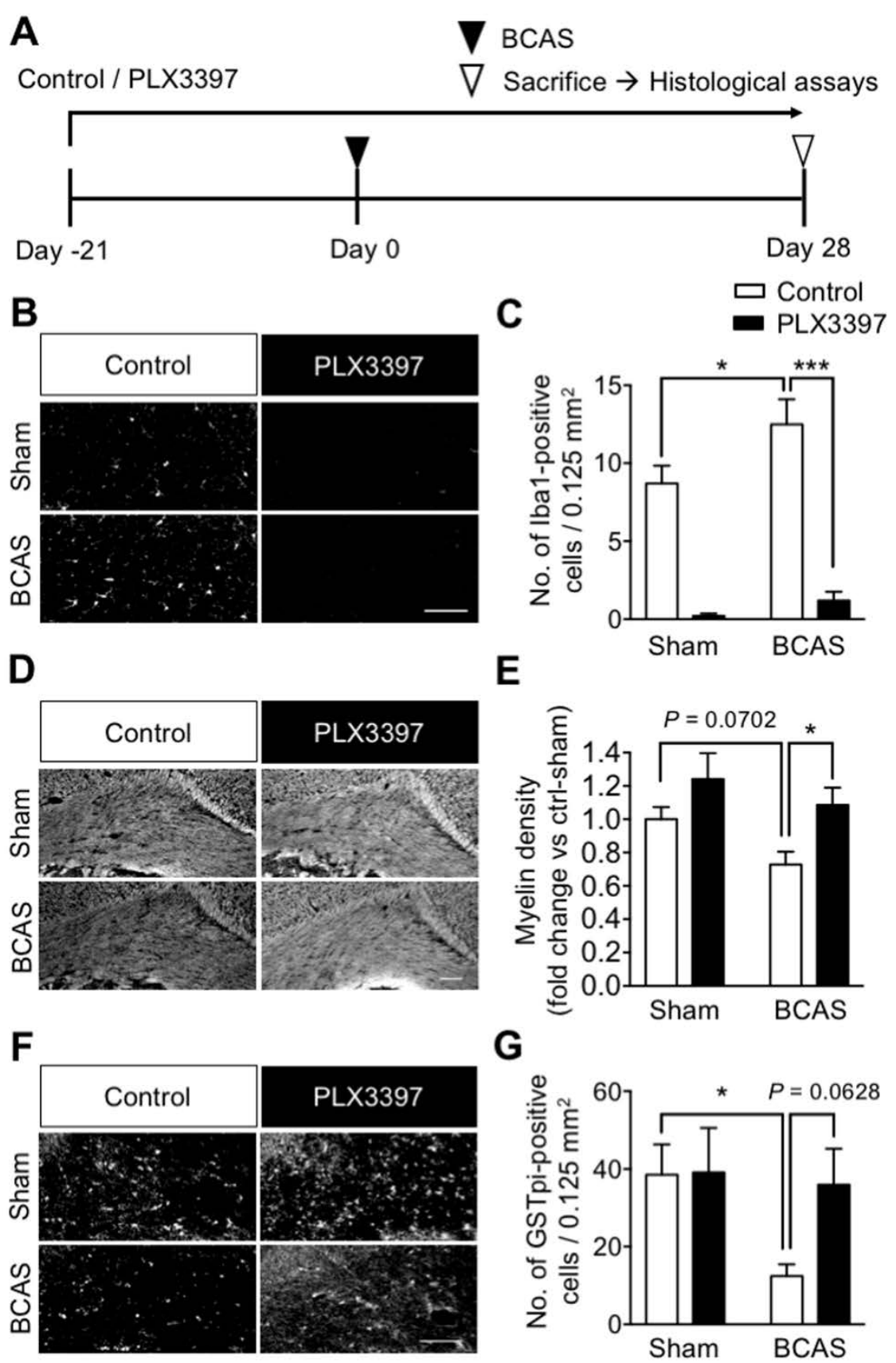


Figure 3
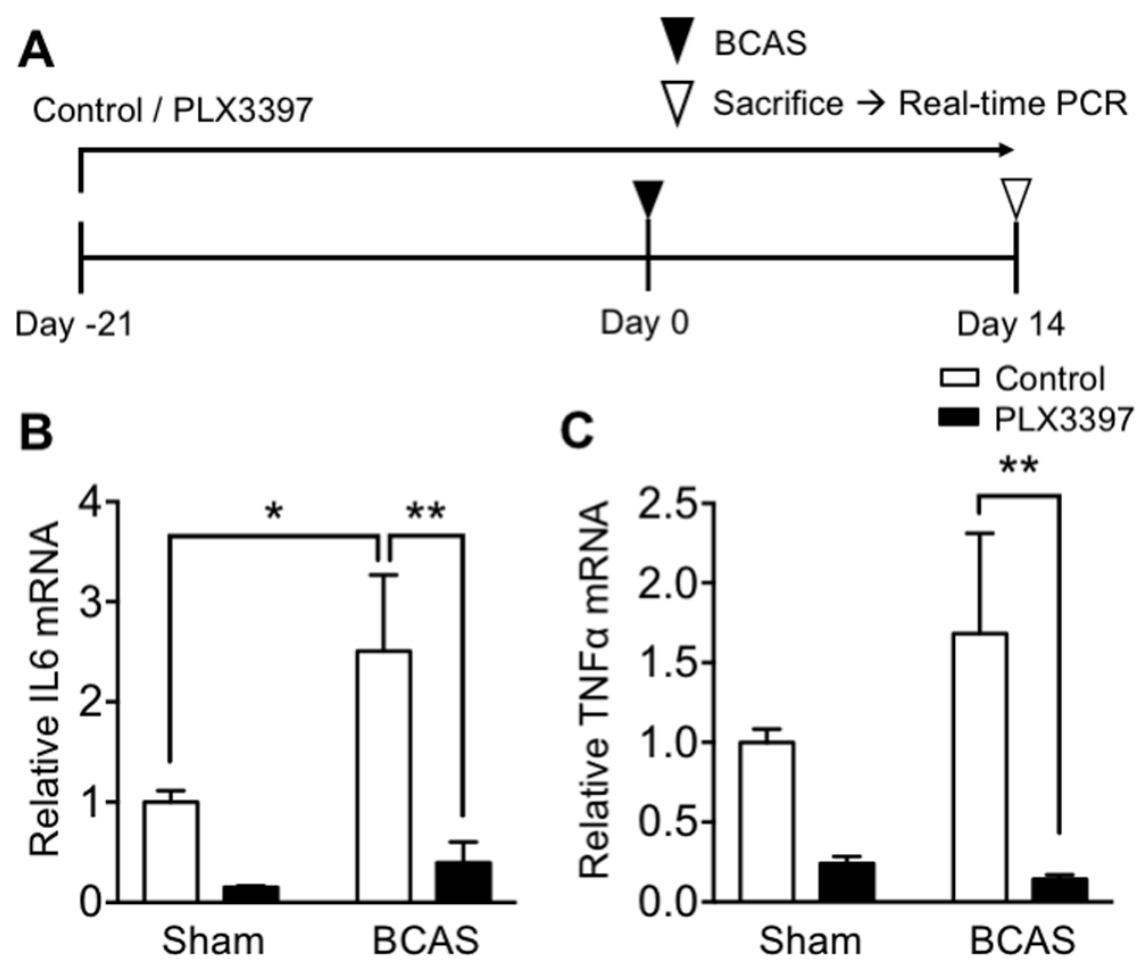